\title{
Respuestas a Sebastián Agüero y a Hugo Seleme*
}

\author{
Jorge F. Malem Seña \\ Universidad Pompeu Fabra \\ jorge.malem@upf.edu
}

\section{DOI: https://doi.org/10.20318/eunomia.2018.4177}

Cuando dos inteligentes y perspicaces colegas y amigos como lo son Sebastián Agüero San Juan y Hugo O. Seleme poseen el buen ánimo para la discusión del libro que nos ocupa, una gran honestidad intelectual para llevarla a cabo y entregan generosamente su tiempo para hacerlo, uno se siente halagado $\mathrm{y}$, a la vez, sorprendido de que ese trabajo haya merecido su atención. $Y$ de inmediato se siente concernido y vivamente comprometido con la grata obligación de tener que ofrecer una respuesta tentativa, aunque sea breve y en algunos puntos, tal vez, con un dejo dogmático por razón del tiempo exigido para su publicación y del espacio con que se cuenta. Soy consciente, además, que la labor académica es una labor colectiva y desinteresada, donde el debate juega un papel central y cuyos frutos se observan casi siempre a mediano o largo plazo. Contribuir modestamente a esa tarea colectiva, continuar el diálogo, en mi caso torpemente, y agradecer a mis discutidores amigos, es lo que me compele a escribir estas líneas y no el deseo de defender numantinamente mi posición. Ambos contradictores saben de mi afecto, mi reconocimiento y mi gratitud hacia ellos, y no solo por sus comentarios a mi libro.

Una primera línea de crítica esbozada por ambos afecta a cuestiones conceptuales y de perspectiva del análisis realizado. En mi defensa diré que, como es sabido, las definiciones y las precisiones conceptuales como las por mí formuladas en Pobreza, corrupción, (in)seguridad jurídica nunca son verdaderas o falsas. De ellas pueden predicarse, en cambio, su adecuación o no al objetivo planteado, su utilidad o inutilidad para el análisis pretendido, etcétera.

Hugo Seleme sostiene que la definición que propongo de corrupción no solo es inútil sino también inadecuada porque contribuye a ocultar o tornar invisibles casos claros de corrupción que una concepción más amplia denotaría con exactitud. Sebastián Agüero, por su parte, me achaca que la tríada escogida para mi análisis, pobreza, corrupción e inseguridad jurídica, pierde eficacia argumentativa y yerra en los diagnósticos y en las soluciones porque no se ha tenido suficientemente en cuenta un aspecto clave que atraviesa toda Iberoamérica: la desigualdad. Trataré de referirme brevemente a ambas observaciones.

Veamos esto con un poco más de detenimiento. Cuando se formula un concepto se corre el riesgo de cometer dos errores: el de la sobre inclusión y el de la infra inclusión. Con el primero, se denota más estados de cosas de los que corresponde, es adecuado o necesario. Con el segundo, a la inversa, se denota

\footnotetext{
* Agradezco a José María Sauca Cano, director de Eunomía. Revista de Cultura de la Legalidad, haber sugerido con generosidad y empeño un debate sobre mi trabajo Pobreza, corrupción, (in)seguridad jurídica. Madrid: Marcial Pons 2017. A él mi más sincero reconocimiento.
} 
menos estados de cosas de lo que corresponde, es adecuado o necesario. Hugo Seleme afirma tajantemente que la definición que asumo tiene el defecto de ser infra inclusiva. Es más, señala que deja fuera de su significado casos típicos de corrupción en América Latina, lo que contribuye a volverlos invisibles y, por lo tanto, a no ser merecedores de reproche alguno.

Estos casos típicos de corrupción que en su opinión quedarían excluidos por mi definición serían, de acuerdo con una enumeración no exhaustiva que ofrece, los siguientes. Cuando incumpliendo sus deberes posicionales un gobernante implementa políticas públicas motivadas por una idea pervertida de la justicia o algún vicio de su carácter o los incumple con el objeto de permanecer en el cargo y mantener así sus propios privilegios. También merecería ser llamado corrupto el gobernante que, incumpliendo sus deberes posicionales, adopta políticas que lo benefician o benefician indebidamente a terceros sin que medie acción por parte de estos últimos.

Ambos estamos de acuerdo en que para que haya corrupción es necesario que el agente que interviene viole alguno de los deberes institucionales que le rigen $\mathrm{y}$, por lo tanto, viola alguna norma de un sistema de referencia. Esto también lo sostiene Ernesto Garzón Valdés, criticado asimismo por Hugo Seleme. Pero aquí acaba, creo, el acuerdo. En mi definición, agrego otros elementos al ya señalado, como es que, en la corrupción, el corrupto persigue la obtención de una ventaja no permitida por el sistema y que hay una relación de causalidad entre el incumplimiento de su deber y la pretensión de obtener ese beneficio para sí o para terceros. Que los actos de corrupción se lleven a cabo en un contexto de discreción surge de que violación de un deber se muestra como una deslealtad hacia la norma violada y, por ese motivo, tiende a ocultarse. Que el acto de corrupción constituya un ilícito penal es una cuestión empírica.

En mi análisis me centro luego en dos formas típicas de corrupción: el soborno y la extorsión. En ambos casos, corruptor y corrompido están identificados y aquí sí funciona el quid pro quo, el intercambio de contraprestaciones. Esto es criticado duramente por Hugo Seleme. A este aspecto atribuye la causa de que infra incluya casos muy graves de corrupción.

No he sostenido que esa clasificación, entre soborno y extorsión, sea exhaustiva y excluyente. Solo he prestado atención a ella por ser la que, a mi juicio, en contra de lo sostenido por Seleme, es la que presenta los casos más usuales. Si lo que mi contradictor quiere decir es que hay casos de corrupción que se perfeccionan mediante la acción de un único agente, tiene razón. La figura jurídico penal de la apropiación indebida, por ejemplo, da cuenta de ello. Si un político o gobernante se apropia indebidamente de dinero o de valores, se corrompe. Incluso podría decirse que tal como está redactado el tipo del cohecho, la acción venal se perfecciona con la mera solicitud de una dádiva sin que tenga que intervenir pasiva o activamente un tercero, solo bastaría su presencia1. Si es esto lo que Hugo Seleme

\footnotetext{
${ }^{1}$ La apropiación indebida, según el artículo 253 del Código Penal español:

1.Serán castigados con las penas del artículo 249 o, en su caso, del artículo 250 , salvo que ya estuvieran castigados con una pena más grave en otro precepto de este Código, los que, en perjuicio de otro, se apropiaren para sí o para un tercero, de dinero, efectos, valores o cualquier otra cosa mueble, que hubieran recibido en depósito, comisión, o custodia, o que les hubieran sido confiados en virtud de cualquier otro título que produzca la obligación de entregarlos o devolverlos, o negaren haberlos recibido.

El cohecho, según el artículo 419:

1.La autoridad o funcionario público que, en provecho propio o de un tercero, recibiere o solicitare, por sí o por persona interpuesta, dádiva, favor o retribución de cualquier clase o aceptare ofrecimiento o
} 
quiere decir estaría plenamente de acuerdo. Pero no creo que las críticas de Seleme se encaminen por ese sendero. $\mathrm{Y}$ lo digo por los casos que sugiere.

Hugo Seleme está pensando que la idea adecuada de corrupción no requiere necesariamente el quid pro quo, ya que en algunos casos como los señalados basta con la presencia de un solo agente, ni tampoco necesita que el corrupto tenga la pretensión de obtener un beneficio no permitido por las instituciones a la cuales presta servicio. Para que se perfeccione la corrupción sería suficiente, en algunas situaciones, que el supuesto corrupto viole deberes institucionales que le corresponden y que esto conduzca a una decisión materialmente injusta, aunque el agente no persiga beneficio alguno. Si actúa movido por odio, resentimiento o simplemente por error también sería corrupto. $E$ igualmente lo sería si es un débil de la voluntad o padece algún vicio en su carácter.

Aquí Seleme extiende de tal manera el significado de corrupción que lo asimila prácticamente al de injusticia o a la inmoralidad, bajo la condición de que sea provocada por la violación de un deber posicional del agente. Esta asimilación tal vez se ve favorecida por algunos de los sentidos que, en el lenguaje ordinario, se usa como correlato de corrupción. Tales como putrefacción, envilecimiento, desintegración ${ }^{2}$. Si se me acusaba por defecto ahora puedo acusar por exceso. La sobre inclusión de casos que esto genera es manifiesta. Una cosa es ser inmoral, la otra es ser corrupto.

Un político homófobo es inmoral, y si viola los deberes de su cargo de perseguir la igualdad, pudiéndolo hacer, también comete ilicitudes, administrativas 0 penales, pero difícilmente se puede calificar como corrupto. Y lo mismo sucede cuando se padecen problemas debidos a ciertas características personales. Se puede decir que el ex presidente argentino Fernando de la Rúa tuviera problemas de salud o que fuera débil de la voluntad. Se puede decir, además, que tomó decisiones que condujeron a la mayor crisis producida en su país en la historia reciente, pero dudo que alguien pueda catalogarlo como corrupto por esa razón. No toda injusticia provocada por el incumplimiento de deberes posicionales puede ser asimilada a la corrupción.

Hay muchos agentes públicos y privados, que por cuestiones personales incumplen con sus deberes y no son acreedores, por ese motivo, a ser tildados como corruptos. El ex presidente argentino Rodríguez Saá, quien ocupó dicho cargo durante siete días, decretó la suspensión de pagos de la deuda externa con los acreedores privados en 2001 y luego se refugió en su casa, en su provincia, San Luis, negándose a regresar a Buenos Aires a la Casa de Gobierno y a continuar en el cargo hasta su renuncia. Todos apuntan a ataques de pánico, entre otras cuestiones. ¿Es por ese motivo un corrupto? Repito, por ese motivo, lo dudo. Pero tal vez Seleme lo incluya en esa categoría. Y no advierto ningún beneficio teórico o práctico en hacerlo.

Otros ejemplos que mi concepción de la corrupción haría invisible por excluidos, según Seleme, pueden ser denotados sin mayores inconvenientes por ella. Tal es el caso de un político que violando los deberes posicionales se beneficia a sí mismo o a personas de su entorno. Trujillo en República Dominicana o Anastasio Somoza en Nicaragua pueden señalarse como casos paradigmáticos.

promesa para realizar en el ejercicio de su cargo un acto contrario a los deberes inherentes al mismo o para no realizar o retrasar injustificadamente el que debiera practicar, incurrirá en la pena de...

2 Son todas acepciones que el Diccionario de la Real Academia ofrece del vocablo corrupción. 
Surgen más reticencias, en cambio, en catalogar como corruptos a quienes ocupando un cargo pretenden perpetuarse en él para mantener sus privilegios o persiguen beneficiar a un sector de la población, o perpetuar la desigualdad social. Estos casos podrían ser tachados de inmorales o injustos, pero, en mi opinión, no toda inmoralidad política es corrupta. El defecto de la sobre inclusión, aquí, parece manifiesto.

En una democracia, por otra parte, la lucha por conseguir el poder político, ejercerlo y conservarlo admite una cierta parcialidad. Cuál es el porcentaje admisible que un capital extranjero puede adquirir en la propiedad de una empresa, rural o urbana, en un mundo globalizado, forma parte de lo políticamente argumentable. La mayoría de los votos, a través del gobierno constituido, se expresa precisamente en este tipo de decisiones. Incluso si ese porcentaje produce injusticias, su determinación será éticamente inaceptable, pero no corrupta.

Las reglas que regulan la democracia permiten una cierta parcialidad y permiten el conflicto, la negociación y hasta la imposición entre partes que representan a ciudadanos. Una corrupción será política si efectivamente viola esas reglas o es cometida por políticos en el ejercicio irregular de su cargo, no si es "única o exclusivamente" inmoral ${ }^{3}$. No estoy seguro de que esta afirmación forme parte de una visión superficial de la corrupción política que opaca, como se me atribuye, una corrupción más profunda. Las reglas del juego político excluyen, en cambio, la expectativa de obtener un beneficio irregular, para sí o para otros, que forma parte efectivamente del núcleo duro de la idea de corrupción.

Las críticas de Sebastián Agüero se dirigen a señalar que la desigualdad permea las tres calamidades por mí reseñadas en el texto de referencia. Y que haberla omitido en mi análisis me conduce necesariamente a un error de concepción $y$, sobre todo, a un error en el diagnóstico y en los remedios sugeridos para su superación.

Efectivamente, coincido con Agüero y también con Seleme en que la desigualdad es una calamidad que afecta sin piedad a los iberoamericanos, y que también colorea otras zonas del planeta. Y asimismo acuerdo con ellos que una mala teoría conduce a una mala práctica. La pregunta aquí es si haber analizado solo tangencialmente la desigualdad en mi escrito supone una mala teoría.

La desigualdad y la pobreza son fenómenos independientes. Entre la persona más rica de la lista Forbes y el último multimillonario por ella señalado hay desigualdad, pero no hay pobreza. Y una de las críticas que se formula a la definición de pobreza basada en la línea de ingreso es precisamente que no permite detectar la desigualdad en la pobreza. Elegí hacer un análisis triádico y no con cuatro vértices porque la independencia entre ellos me lo permitía. Precisamente porque son independientes es que se puede establecer diferentes relaciones entre los elementos analizados.

No obstante, he intentado mostrar, acepto que de soslayo, que existe una especie de circularidad causal entre pobreza y desigualdad. Al hablar de las "trampas de la pobreza" manifesté que los pobres, dejados a su suerte, sin la intervención del Estado, tienden a perpetuarse y a reproducirse. En una sociedad heterogénea esto supone la consolidación de la desigualdad.

\footnotetext{
3 Por oposición también a la corrupción privada.
} 
Esta existente desigualdad, a su vez, impide la igualdad de oportunidades y provoca una desigualdad en los resultados. En ese esquema la desigualdad también tiende a perpetuarse. Estoy en completa sintonía con Sebastián Agüero en este punto. $Y$ también comparto con él y con Seleme que un aumento de la riqueza no necesariamente disminuye la desigualdad, y creo que no en todos los casos palía la pobreza.

Sebastián Agüero observa que cuando las élites económicas capturan el Estado no necesitan del instrumento de la corrupción para alcanzar sus objetivos, a diferencia de Seleme que en ello ve la corrupción a un nivel más profundo. Hacerse con el gobierno supone disponer de todos los recursos legales para obtener beneficios sin consideración a prácticas ilícitas algunas.

El corolario sería que un Estado gobernado por ricos debería ser, en definitiva, un Estado no corrupto. No creo que esto sea lo sostenido, sin embargo, por Agüero. En primer lugar, porque existe la suficiente evidencia empírica de que élites gobernantes muy ricas son muy corruptas. $Y$, en segundo lugar, porque las élites no siempre conforman un todo homogéneo y armonioso. $Y$ puede ser que una facción necesite, en un momento dado, la artimaña de la corrupción para conseguir objetivos de otro modo más costosos o inalcanzables. En ese sentido, puede darse la corrupción horizontal entre iguales o situados en un mismo nivel o estrato social. No es necesaria la desigualdad vertical, aunque sí que los involucrados dispongan de la posibilidad de comprar o de vender contraprestaciones corruptas.

La pobreza en una situación de desigualdad afecta a la seguridad jurídica. Acuerdo con Agüero. Quienes se encuentran en las escalas sociales más bajas necesariamente soportarán niveles de injusticia inadmisibles respecto de todos los ámbitos de la vida. En estos contextos, la vida en democracia, libre de temores y digna, se vuelve una quimera.

Sea que establezcamos relaciones entre la pobreza, la corrupción y la inseguridad jurídica o agreguemos a ellas la desigualdad social, a los involucrados en este debate nos interesa saber qué medidas son conducentes a la erradicación de estas calamidades que tanto nos afectan.

Lo primero que habría que admitir es que conforman un todo sistémico y que como tal no valen medidas aisladas, alejadas de una visión del conjunto. Para Estados como los iberoamericanos empezar con la lucha contra la corrupción y a favor de la seguridad jurídica puede ser un comienzo esperanzador. Ninguna política pública es eficaz con los altísimos niveles de corrupción reinantes en esa zona geográfica.

Debo aceptar dos consideraciones cautelares. La primera: en ocasiones, se invoca una supuesta lucha contra la corrupción para ocultar otros problemas económicos, políticos y sociales igualmente acuciantes. Otras veces, se aduce cuestiones de diversa índole para tapar casos de corrupción. Para luchar contra la corrupción se requiere no solo honestidad, es necesario valentía y determinación. La segunda: la seguridad jurídica se disfruta en grados diversos, según los distintos actores sociales. En el régimen de los Duvalier en Haití, las grandes empresas transnacionales, especialmente estadounidenses, disfrutaban de una relativa seguridad jurídica entendida en sentido objetivo y subjetivo, mientras que esto no existía para el grueso de la población. La democracia nos exige que la seguridad jurídica esté a disposición de todos los ciudadanos por igual. Tiene aquí razón Sebastián Agüero al subrayar la importancia de la desigualdad. 
Sin luchar contra la corrupción tal vez no sea posible acabar con la pobreza. Los corruptos no son reformadores, ni revolucionarios. Les interesa mantener el estatus quo para continuar gozando de sus irregulares privilegios. Y si la pobreza forma parte de ese contexto venal no tendrán incentivos para enfrentarse a ella. Hay que eliminar la pobreza cuanto antes. Los efectos que tiene sobre nuestras vidas son incontables y permanentes. La pobreza nos define como individuos y como sociedad.

Y, por cierto, hay que garantizar niveles de igualdad, que no de igualación, que permitan el disfrute de los derechos más básicos y que contribuyan a que todos gocen de una vida digna. Para todo ello no parece que exista una alternativa a la vigencia de un Estado de derecho. 